\title{
Relationship between Air Pollution and Lung Cancer in Fujian Province: A Case-control study
}

Guang-Min Chen

Fujian Center for Disease Control and Prevention https://orcid.org/0000-0001-9103-5193

Fei He

Fujian Medical University,Fujian Provincal Key Laboratory of Environment factors and Cancer;key laboratory of ministry of education for gastrointestinal cancer

Jiasheng Wu

Administration of Fuzhou area of China(Fujian囚 Pilot Free Trade Zone

Huimin Yang

Fujian Medical University

Jin Su

Fujian Provincial Environmental Monitoring Center Station

Jianbo Lin

The first affiliated hospital of Fujian Medical University

Zhiqiang Liu

The united innovation of Mengchao hepatobiliary technology keylaboratory of Fujian Province;Mengchao Hepatobiliary Hospital of Fujian Medical University Jianfeng Xie

Fujian Provincial center for disease control and prevention

Liang Bai

Fujian Medical University

Lin Cai

Fujian Medical University

Kuicheng Zheng ( $\square$ cgmyf34567@163.com)

Fujian Center for Disease Control and Prevention

Research article

Keywords: Lung cancer, air pollutants, PM10, PM2.5, ozone

Posted Date: November 15th, 2019

DOI: https://doi.org/10.21203/rs.2.17362/v1

License: (c) (1) This work is licensed under a Creative Commons Attribution 4.0 International License. Read Full License 


\section{Abstract}

Background: Outdoor air pollutants, especially particulate matters, are defined as a type of carcinogen by the International Agency for Research on Cancer. Studies have shown that air pollution is associated with lung cancer morbidity or mortality. This study is aimed at exploring the relationship between air pollutants and primary lung cancer in Fujian Province, China.

Methods: We conducted a hospital-based, retrospective, case-control epidemiological study on three different populations to assess the occurrence of lung cancer caused by exposure to various levels of air pollution.

Results: The total study population comprised 885 lung cancer patients and 1,220 healthy controls. The following parameters were identified as risk factors for lung cancer among the total population: smoking; exposure to cooking oil fumes; passive smoking; medical history of lung disease; family history of lung cancer; and exposure to PM10, PM2.5, and 03. Fruit intake and physical exercise were protective against lung cancer. For smokers, medical history of lung disease, family history of lung cancer, and exposure to PM10, and PM2.5 were risk factors for lung cancer, while fruit intake and physical exercise were protective factors. Among non-smokers, exposure to cooking oil fumes; medical history of lung disease; family history of lung cancer; and exposure to PM10, PM2.5, and 03 were factors increasing the risk of lung cancer, while fruit intake, physical exercise, and tea drinking were protective.

Conclusions: Long-term exposure to PM10, PM2.5, and 03 was found to be significantly associated with increased risk of lung cancer, with the risk being greater for non-smokers and persons exposed to cooking oil fumes.

\section{Background}

As per GLOBOCAN 2018, approximately 18.1 million new cancer cases are diagnosed worldwide each year. Lung cancer ranks first among the causes of new cancer cases, with about 2.09 million cases diagnosed annually, accounting for $11.6 \%$ of new cases of malignant tumors. The incidence of lung cancer in East Asia, particularly in China, is far higher than that worldwide (more than 40/100 000) ${ }^{1}$. Lung cancer was the leading cause of cancer incidence and mortality in China for many years ${ }^{2}$. According to the 2017 Malignant Tumors report from Fujian Province, lung cancer ranked first among all types of cancers in males (62.61/100 000) and second in females (24.8/100 000). Clearly, lung cancer has become a serious threat to public health and places a heavy disease burden in Fujian Province and China as a whole.

Smoking is a known and confirmed risk factor for lung cancer. The increase in the number of female smokers in developed countries is one of the reasons for the increase in the incidence of lung cancer among women and decrease in the comparative incidence among men ${ }^{3}$. However, some studies have found that about $15 \%$ of men and $53 \%$ of women with lung cancer do not smoke. Moreover, about $25 \%$ of lung cancer cases worldwide cannot be attributed to tobacco usage $^{4}$. This has led to an increased interest in the exploration of the causes of lung cancer other than smoking, particularly air pollution ${ }^{5}$, diet ${ }^{6}$, infection ${ }^{7,8}$, cooking fumes ${ }^{9}$, medical history of respiratory diseases ${ }^{10}$, and occupational exposure ${ }^{11}$.

For nearly 50 years, research has been underway to confirm the relationship between outdoor air pollution and lung cancer ${ }^{12}$. The International Agency for Research on Cancer (IARC) defines outdoor air pollutants, especially particulate matter, as a type of carcinogen. This classification is primarily based on evidence that long-term persistence of high average concentrations of $\mathrm{PM}_{2.5}$ in outdoor air is associated with lung cancer morbidity or mortality ${ }^{13}$. However, the IARC report is a qualitative assessment of hazard identification, and it does not provide the relative risk or odds ratio (RR or OR) of lung cancer associated with outdoor air pollution. The current research results still leave several key points unclear. First, the population groups that are most vulnerable to air pollution are yet to be identified ${ }^{14-17}$. Second, few studies have focused on the dose-response relationship between long-term exposure to outdoor air pollution and lung cancer ${ }^{16,18,19}$. In particular, very few studies from China have investigated the risk of lung cancer in relation to air pollution; among these studies, case-control studies and cohort studies are very few, and most of the existing studies focus on lung cancer mortality.

Given the limitations of epidemiological research methods, cohort studies on the causal relationship between outdoor air pollution and lung cancer would require a long time to yield conclusive results. In this study, we sought to conduct a hospital-based, case-control study to investigate the relationship between air pollutants and lung cancer in Fujian Province, with special focus on the exposure levels of different population groups to air pollutants. We expect that the results of this study would provide a scientific basis for targeted improvement of the atmospheric environment for protection of public health.

\section{Materials And Methods}

\section{Study subjects}

Between January 2010 and December 2015, we recruited from three sources: Department of Thoracic Surgery and Respiratory Medicine of the First Affiliated Hospital of Fujian Medical University, Union Hospital Affiliated to Fujian Medical University, and Fuzhou General Hospital of Nanjing Military Region. Patients were included if they had been newly diagnosed with primary lung cancer, as confirmed by fiberoptic bronchoscopy or surgical histopathology, and had resided in Fujian province of China for more than 10 years.

The population-based approach was applied to the recruit the control group, which comprised healthy community dwellers randomly selected from the resident records of Fujian province. The control group was frequency-matched to the cases by ethnicity, gender, and age. Every control subject was of ages \pm 2 years as compared to the matching cases. All the selected control individuals successfully met the inclusion criteria and completed the study, without any drop-out during the study. 
In total, the case group comprised 885 patients with lung cancer, while the control group comprised 1,220 healthy individuals. All participants provided written, informed consent before undergoing the examination. The study protocol was approved by the Ethics Committee of Fujian Medical University.

\section{Questionnaire and variables}

All participants were surveyed using a standardized questionnaire, which was administered during a scheduled phone interview conducted via a study team member. The 18-page questionnaire had questions pertaining to the patients' demographic characteristics information, tumor characteristics, and data regarding the subject's living environment, dietary habits, smoking history, alcohol consumption, intensity of physical activity, occupational exposure to air pollutants, and exposure to domestic pollutants. The questionnaire also included items regarding medical history, family history, and lifestyle-related parameters. Data regarding reproductive health were collected for female participants.

Body mass index (BMI) was determined as the ratio of body weight $(\mathrm{kg})$ and height $[\mathrm{m}]^{2}$. A positive smoking history was defined as a history of having smoked more than 100 cigarettes during his/her lifetime. Passive smoking history was defined by non-smoking history of inhaling cigarette smoke generated by others or exposure to exhaled smoke more than 15 minutes per day. A history of alcohol consumption was defined as drinking at least one alcoholic beverage per week for more than six months, irrespective of the type of alcoholic drink. Drinking tea was defined as consuming at least one cup of any kind of tea per week for more than six months. A family history of cancer was defined as the occurrence of a malignant tumor in first-degree or second-degree relatives. Occupational physical activity was rated as low, moderate, or high intensity, as defined by the Reference Standard of Labor Intensity recommended by the Chinese Nutrition Society in 2000 . To check for exposure to cooking oil fumes, participants were enquired about whether their degree of exposure to fumes in the kitchen was none (no exposure), light, moderate, or heavy ${ }^{20}$.

\section{Overview of the study area}

Fujian Province is located on the southeast coast of China. The land area is 124000 square kilometers in total. From north to south, the province measures about 530 kilometers and occupies about 480 kilometers from east to west. Fujian is located at a latitude of $23^{\circ} 30^{\prime}$ and $28^{\circ} 22^{\prime}$ north and at longitude of $115^{\circ} 50^{\prime}$ and $120^{\circ} 40^{\prime}$ east. The terrain is higher in the northwest and lower in the southeast. About $90 \%$ of the total land area of the province is covered by mountains and hills. In addition, the coastal landform pattern is dominated by a tortuous coastline that includes several bays and peninsulas. The climate in Fujian Province is subtropical monsoon climate, which makes the area warm and humid. The annual average temperature is $15^{\circ} \mathrm{C}-22^{\circ} \mathrm{C}$, which increases from the northwest to the southeast. The annual average precipitation is $800-1,900 \mathrm{~mm}$, with the the precipitation being greatest between May and June every year, with several typhoons occurring at the turn of summer and autumn.

\section{Air pollution data collection}

For this study, we aimed to obtain a reasonable estimate of each subject's exposure to atmospheric pollutants by using a longer average annual concentration. The levels of sulfur dioxide $\left(\mathrm{SO}_{2}\right)$, nitrogen dioxide $\left(\mathrm{NO}_{2}\right)$ and suspended particulates smaller than $10 \mu \mathrm{m}$ in aerodynamic diameter $\left(\mathrm{PM} \mathrm{M}_{10}\right)$ in Fujian Province were obtained from the complete monitoring data of national control points, which has been maintained since 2005. Since 2013, China has implemented new monitoring standards, which include the current maximum of eight hours average for ozone $\left(\mathrm{O}_{3}\right)$. Accordingly, the maximum value of continuous 8-hour ozone concentration in a day is taken as the standard for evaluating the ozone pollution level of the same day and the six indicators of air quality are monitored: $\mathrm{SO}_{2}, \mathrm{NO}_{2}, \mathrm{PM}_{10}$, carbon monoxide (CO), and suspended particulates smaller than $2.5 \mu \mathrm{m}$ in aerodynamic diameter ( $\mathrm{PM}$..5). The ambient air quality data collected in this study was collected for the period between January 1, 2005 and December 31, 2015.

The daily average concentration values and monthly average values of $\mathrm{SO}_{2}, \mathrm{NO}_{2}, \mathrm{PM}_{10}, \mathrm{CO}, \mathrm{O}_{3}$, and $\mathrm{PM}_{2.5}$ were collected for 39 monitoring points (national control points) in Fujian Province; the data were collected from the Fujian Provincial Environmental Monitoring Center Station (Figure 1). The strategic value of the location of each monitoring point has been demonstrated previously, and the points have been shown to be geographically representative. The air pollution monitoring data for $\mathrm{SO}_{2}, \mathrm{NO}_{2}, \mathrm{PM}_{10}, \mathrm{CO}, \mathrm{O}_{3}$, and $\mathrm{PM}_{2.5}$ were evaluated according to the Chinese Ambient Air Quality Standard (GB3095-2012).

Since it would be impractical to measure the individual exposure level to concentrations of atmospheric pollutants by having each subject wear a monitoring device, we used an individual atmospheric pollutant exposure estimation method, according to the approach proposed by Dadvand et al ${ }^{21}$. Basically, we constructed an algorithm to predict atmospheric pollutant exposure for each location within Fujian province by integrating air pollution monitoring data and spatial coordinates of 39 monitoring points. By using the spatial prediction function of ArcGIS 10.3, the spatial distribution map of air pollution indexes in Fujian Province was generated by applying inverse distance to a power (IDW) interpolation in areas that lacked derived data. The annual average level of cumulative concentration served as the matched measurement data for each index. Further, the levels of $\mathrm{SO}_{2}, \mathrm{NO}_{2}$, and $\mathrm{PM}_{10}$ were the annual average values from 2005 to the time that subjects enrolled. In addition, the concentrations of $\mathrm{O}_{3}, \mathrm{CO}$, and $\mathrm{PM}_{2.5}$ were measured from 2013 to the time of enrollment of the subjects. According to the detailed home address (specific to the district, street, and house number), the spatial coordinates (latitude and longitude) of each subject was accurately determined by GPSspgxGeo coding software and Tencent map software, which can be further mapped to the predicting model and used to generate the estimating pollution data for each subject.

\section{Statistical analysis}

The Chi-square test was used to compare the general characteristics of cases and controls. Stratified analysis for different populations was performed using a $t$ test for the exposure levels of air pollution indexes. Unconditional logistic regression modeling and identification of possible confounding factors were performed by calculating odds ratios (ORs) and 95\% confidence intervals (Cls) for air pollution indexes and lung cancer risk. All analysis was performed using the SPSS 25.0 software package (IBM Corporation, Armonk, New York, USA) and ArcGIS 10.3 (ESRI Inc, USA). All p-values were based on a two-sided test with an a of 0.05 . 


\section{Results}

\section{Demographic characteristics of the study subjects}

The current study comprised 2,105 subjects, including 885 cases and 1,220 controls. Subjects included 1,354 males and 751 females, with ages between 23 and 90 years of age and average age of $58.94 \pm 10.73$ years. The case and control groups did not show any significant difference in the distribution of gender, age, ethnicity, and marital status $(P>0.05)$. However, significant intergroup differences were noted in the educational level, occupation, and $B M I(P<0.05)$.

Among the smokers, no significant difference was noted between the case group and the control group in terms of the distribution of gender, ethnicity, and marital status $(P>0.05)$. However, statistically significant intergroup differences were noted in the distribution of education, occupation, and $B M I(P<0.05)$. Among the non-smokers, the case group and control groups did not differ significantly in the distribution of age, ethnicity, and marital status ( $>0.05)$, but showed significant differences in gender, education level, and occupational exposure $(P<0.05)$.

Among the 885 cases included, 551 (62.3\%) were of adenocarcinoma, 208 (23.5\%) were of squamous cell carcinoma, and 126 (14.2\%) were of other pathological types of cancers. Among the 519 smokers, 253 (48.7\%) had adenocarcinoma, 177 (34.1\%) had squamous cell carcinoma, and 89 (17.4\%) had tumors of other pathological types. Of 366 non-smoking lung cancer patients, 298 (81.4\%) had adenocarcinoma, 31 ( $8.5 \%$ ) had squamous cell carcinoma, and 37 (10.1\%) had lesions of other pathological types (Table 1).

\section{The risk factors of lung cancer}

In this study, we explored the potential factors for lung cancer in the three groups: general population, smokers, and non-smokers (Table 2). Of the total population, after adjusting for BMI, education, and occupation, we found that subjects with a family history of lung cancer or medical history of lung disease, drinking alcohol, smoking, passive smoking, or exposure to cooking oil fumes were susceptible to lung cancer. We found that the risk of lung cancer was low for subjects who performed physical exercise and had a regular intake of fruit (more than 3 times per week). Among the smokers, after adjustment for age, BMI, education, and occupation, the risk factors for lung cancer were family history of lung cancer, medical history of lung disease, and exposure to cooking oil fumes, while the protective factors were physical exercise and fruit intake. Similarly, for non-smokers, the risk factors for lung cancer were family history of lung cancer, history of lung diseases, passive smoking, and exposure to cooking oil fumes, after adjustment for gender, education, and occupation, whereas the protective factors were drinking tea, physical exercise, and fruit intake.

\section{Univariate analysis of levels of exposure to atmospheric pollutants in different populations}

The annual average of $\mathrm{SO}_{2}, \mathrm{NO}_{2}$, and $\mathrm{PM}_{10}$ concentrations for the period between 2005 and 2015 and those of $\mathrm{CO}$, $\mathrm{PM}_{2.5}$, and $\mathrm{O}_{3}$ for the period 2013-2015 are shown in Figure 2. Notably, the distribution of different pollutants differed from one another. Thus, we noted that $\mathrm{NO}_{2}, \mathrm{PM}_{2.5}$, and $\mathrm{O}_{3}$ had similar distribution patterns, with the pollutants being highly aggregated in cities along east coast; this may be associated with the dense population and severe traffic pollution. The remaining three common pollutants showed completely different distribution patterns, with $\mathrm{CO}$ mainly concentrating in northeast area, $\mathrm{SO}_{2}$ aggregating in the mid-west region, and $\mathrm{PM}_{10}$ mainly affecting the southwest. The discrepancy in the distribution patterns may be attributed to the complex effect of factory contamination and factors such as climatic and geographic conditions.

Univariate analysis was performed to levels of exposure to evaluate the impact of atmospheric pollutants on different populations. The values for concentrations of atmospheric pollutants were classified into four levels based on \pm 1 standard deviation (Table 3 ). For the total population, after adjustment for education, occupation, BMI, family history of lung cancer, and medical history of lung disease, alcohol consumption, smoking, passive smoking, exposure to cooking oil fumes, physical exercise, and fruit intake, the results showed that the risk of developing lung cancer with exposure to $\mathrm{NO}_{2}$ concentrations of $0.019-0.029\left(\mathrm{mg} / \mathrm{m}^{3}\right)$ was 1.356 times greater than at concentrations of less than $0.019\left(\mathrm{mg} / \mathrm{m}^{3}\right)(95 \% \mathrm{Cl}$ : $1.028-1.788)$. As compared to exposure to PM 10 concentrations of less than $0.051\left(\mathrm{mg} / \mathrm{m}^{3}\right)$, exposure to concentrations of $0.051-0.057\left(\mathrm{mg} / \mathrm{m}^{3}\right)$ increased the risk of developing lung cancer by 2.450 times greater (95\% Cl: $1.728-3.474)$, while exposure to concentration of $0.057-0.064\left(\mathrm{mg} / \mathrm{m}^{3}\right)$ and increased the risk by 1.637 times $(95 \% \mathrm{Cl}$ : $1.178-2.276)$.

Exposure to $\mathrm{PM}_{2.5}$ is also a risk factor for lung cancer. For exposure to concentrations of $0.020-0.027\left(\mathrm{mg} / \mathrm{m}^{3}\right)$, the $\mathrm{OR}$ was $33.658(95 \% \mathrm{Cl}$ : $15.450-73.325)$, and for exposure to concentrations of $0.027-0.035\left(\mathrm{mg} / \mathrm{m}^{3}\right)$, the $\mathrm{OR}$ was $5.059(95 \% \mathrm{Cl}: 2.390-10.712)$. Furthermore, exposure to $\mathrm{O}_{3}$ is also a risk factor for lung cancer. For exposure to $\mathrm{O}_{3}$ concentrations of $0.047-0.065\left(\mathrm{mg} / \mathrm{m}^{3}\right)$, the OR was 125.056 (95\% Cl: 29.902-523.012); 17.746 (95\% Cl: 4.322-72.862), for $\mathrm{O}_{3}$ concentrations of $0.065-0.083\left(\mathrm{mg} / \mathrm{m}^{3}\right)$; and $50.896(95 \% \mathrm{Cl}: 11.069-234.032)$ for concentrations of more than $0.083\left(\mathrm{mg} / \mathrm{m}^{3}\right)$.

Next, we compared the results for smokers, after adjusting for age, education, occupation, BMI, family history of lung cancer, and medical history of lung disease, exposure to cooking oil fumes, physical exercise, and fruit intake. Further, for non-smokers, the results were compared after adjusting for gender, education, occupation, family history of lung cancer, medical history of lung disease, passive smoking, exposure to cooking oil fumes, drinking tea, physical exercise, and fruit intake. The analysis indicated that for both groups, exposure to $\mathrm{PM}_{10}$ and $\mathrm{PM}_{2.5}$ was a risk factors for lung cancer. Moreover, exposure to $\mathrm{PM}_{2.5}$ had a greater impact on non-smokers than on smokers, as shown by the following results for both groups: OR was 61.431 (95\% $\mathrm{Cl}$ : 18.041-209.181) and 24.545 (95\% Cl: 8.12-74.265) (in non-smokers and smokers, respectively, for exposure to $\mathrm{PM}_{2.5}$ concentrations of $0.020-0.027$ (mg/m ${ }^{3}$ )) and $0 \mathrm{R}$ was

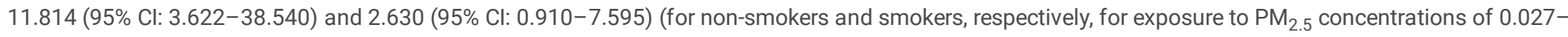
$0.035\left(\mathrm{mg} / \mathrm{m}^{3}\right)$. Since none of the participants were exposed to $\mathrm{O}_{3}$ concentrations of less than $0.047 \mathrm{mg} / \mathrm{m}^{3}$ in the control group, the effect of $\mathrm{O}_{3}$ exposure on the smokers could not be assessed. Among the non-smokers, exposure to $\mathrm{O}_{3}$ was identified as a risk factor for lung cancer. However, $\mathrm{SO}_{2}$ and lung cancer did not show any associated, both in the general population and in the group of smokers or non-smokers. Similarly, none of the participants in the control group were exposed to a low concentration of $\mathrm{CO}$, and therefore, the association of $\mathrm{CO}$ with lung cancer could not be evaluated (Table 3 ).

Page 4/14 
We also analyzed the relationship between air pollution and lung cancer stratified by passive smoking and exposure to cooking oil fumes, and the results were consistent with those of smoking. The detailed results are shown in Additional Table 1 to 3 (for passive smoking) and Additional Table 4 to 6 (for cooking oil fume exposure).

\section{Multivariate analysis of levels of exposure to atmospheric pollutants in different populations}

All the variables that were found to have a significant impact on the development of lung cancer in the previous analysis were further subjected to multi-factor unconditional logistic regression analysis using the backward stepwise method. We used $\mathrm{P} \leq 0.05$ as the inclusion criterion and $\mathrm{P} \geq 0.10$ as the exclusion criterion. The results of the analyses indicated that the following factors increased the risk of lung cancer among the general population: smoking; exposure to cooking oil fumes; passive smoking; medical history of lung disease; family history of lung cancer; and exposure to $\mathrm{O}_{3}, \mathrm{PM}_{10}$, and $\mathrm{PM}_{2.5}$. On the other hand, fruit intake and physical exercise were found to be protective factors against risk of lung cancer (Table 4). For smokers, medical history of lung disease; family history of lung cancer; and exposure to $\mathrm{PM}_{10}$, and $\mathrm{PM}_{2.5}$ were factors that increased the risk of lung cancer, whereas fruit intake and physical exercise were factors that reduce the risk of lung cancer (Table 5). Similarly, among the non-smokers, cooking oil fumes; medical history of lung disease; family history of lung cancer; exposure to $\mathrm{PM}_{10}, \mathrm{PM}_{2.5}$, and $\mathrm{O}_{3}$ may increase the risk of lung cancer, while fruit intake, physical exercise, and drinking tea were found to protect against the risk of lung cancer (Table 6).

The results of the analysis in different populations are shown in Additional Table 7-9 for passive smoking and in Additional Table 10-12 for exposure to cooking oil fumes.

\section{Discussion}

This hospital-based case-control study was designed to evaluate the relationship between atmospheric concentrations of air pollutants and the occurrence of lung cancer in Fujian Province. We found that the overall risk factors for lung cancer were smoking; exposure to cooking oil fumes; passive smoking; medical history of lung disease; family history of lung cancer; and exposure to $\mathrm{PM}_{10}, \mathrm{PM}_{2.5}$, and $\mathrm{O}_{3}$. Fruit intake and physical exercise were identified as protective factors. Our results on the risk factors are consistent with those of several previous reports. We found that long-term exposure to $\mathrm{PM}_{10}, \mathrm{PM}_{2.5}$, and $\mathrm{O}_{3}$ was significantly associated with an increased risk of lung cancer, and the risk appears to be greater in non-smokers than in smokers or the general population. Further, this difference appears to be even greater for people exposed to cooking oil fumes than among those without such an exposure.

In the recent past, extensive research has been conducted in China on the short-term health effects of air pollution ${ }^{22,23}$. However, studies exploring the longterm effects of air pollution on health, particularly those employing more reliable methods such as cohort studies, have been scarce. Most of the studies conducted thus far are related to mortality ${ }^{24-27}$. In recent years, China has been making continuous improvement in air pollution monitoring system. However, China is a vast country. Therefore, further investigation is necessary to evaluate the exposure characteristics, dose-risk models, and long-term health risks of single or multiple pollutants in different regions.

At present, there is a strong research focus on the relationship between air pollution and lung cancer. Studies ${ }^{28,29}$ have reported that long-term exposure to $\mathrm{PM}_{2.5}, \mathrm{NO}_{2}, \mathrm{NO}_{\mathrm{x}}$, and $\mathrm{SO}_{2}$ is significantly associated with an increased risk of lung cancer. Such associations have been shown to hold true for both smokers and non-smokers as well as men and women, with the impact being the same for all groups. For non-smokers, exposure to outdoor PM 2.5 is greater for patients with lung cancer and exhibits a linear dose-response relationship ${ }^{30}$. The results of the ACS CPS-II study ${ }^{31}$ and the European Air Pollution Impact Cohort Study (ESCAPE) ${ }^{5,32}$ have also demonstrated a positive correlation between exposure to outdoor $\mathrm{PM}_{2.5}$ and the occurrence of lung cancer. Our results had a wide $95 \% \mathrm{Cl}$ range, which might be attributed to the small sample size in our study, but our results also suggested that $\mathrm{PM}_{10}$ and $\mathrm{PM}_{2.5}$ were risk factors for lung cancer. Similar to our study, the study by Yang et al. ${ }^{28}$ also revealed that the association of $\mathrm{PM}_{2.5}$ with lung cancer (RR $=1.18$ ) was more pronounced in non-smokers than in the general population ( $R R=1.07)$. However, because of the limited number of studies included $(n=3)$ and a wide overlap between the general population and people who never were smokers, the controversy still remains regarding whether there is a connection between lung cancer and air pollution. Currently, there is still no report on the effect of exposure to cooking oil fumes on individuals.

Gerard Hoek et al. ${ }^{33}$ investigated the risk of lung cancer in the general population associated with exposure to ambient air pollution. They used the population attributable risk fraction (PAF) indicator, which describes the fraction of lung cancer incidence in the general population that can be prevented by eliminating $\mathrm{PM}_{2.5}$ exposure. The proportion of the population with lung cancer was found to be between $28.6 \%$ and $86.7 \%$ when $\mathrm{RR}=1.5$ and the concentration of $\mathrm{PM} 2.5$ was reduced by $10-60 \mu \mathrm{g} / \mathrm{m}^{3}$. The RR value of ambient air pollution was found to be much smaller than that for active smoking; however, air pollution affects the entire population. Thus, a reduction in the concentration of $\mathrm{PM}_{2.5}$ will result in a substantial reduction in the incidence of lung cancer in the overall population.

Study results on the association between long-term exposure to $\mathrm{O}_{3}$ and lung cancer have been contradictory, with some studies showing a positive ${ }^{34,35}$, negative $\mathrm{e}^{36,37}$, or invalid association ${ }^{38}$. In our study, the OR value of $\mathrm{O}_{3}$ was $17.746-125.056(P<0.05)$. Since the resulting $95 \% \mathrm{Cl}$ was wide, this could suggest that $\mathrm{O}_{3}$ may be a risk factor for lung cancer. Recently, N. Rocks et al. ${ }^{39}$ measured the migration of tumor cells using the Boyden chamber test. They also established a mouse model- and employed an automated tumor recognition software with supervised classification to quantify the spread of lung tumor cells. Their results showed that exposure to $\mathrm{O}_{3}$ enhanced lung cancer cell proliferation and migration. This was strong evidence for the causative relationship between $\mathrm{O}_{3}$ exposure and lung cancer.

In our study, we examined only the relationship between lung cancer and air pollution, but not the specific underlying biological mechanisms. Currently, two main explanations have been proposed to explain this relationship. First, exposure to atmospheric pollution can cause oxidative stress, and which may cause 
macrophages to release reactive oxygen species (ROS) that can damage DNA, protein, and lipid cells. Additionally, ROS production may be triggered by metals present on the surface of particulate matter through the Fenton reaction or anthraquinones in the redox cycle. Second, exposure to air pollutants may directly or indirectly induce inflammatory effects, which may lead to the generation of chemokines and cytokines, thereby inducing angiogenesis and transforming epithelial cells into malignant and invasive cells, which ultimately invade distal organs ${ }^{40,41}$

The current study has a few limitations. First, the study was conducted with a hospital case-control design and, therefore, it has flaws that are inherent in the method itself. To overcome this, various control measures, such as selecting cases from multiple hospitals and choosing objective indicators, were employed in this study. However, most of the controls were from Fuzhou, and the difference in the regional distribution of cases and controls may have influenced the results. Second, although the locations of the atmospheric sampling points were established scientifically and were reasonable, the air quality in Fujian Province that was analyzed in this study may not completely reflect the air quality of the entire Fujian Province because of the limited number of sampling points. Third, the levels of $\mathrm{SO}_{2}, \mathrm{NO}_{2}$, and $\mathrm{PM}_{10}$ were measured since 2005, while those of $\mathrm{O}_{3}, \mathrm{CO}$, and $\mathrm{PM}_{2.5}$ were obtained since 2013. The difference in the data collection period for the two set of parameters may have influenced the results. Fourth, the concentrations of the air pollutants measured in the indices of this study were not obtained by individual portable monitoring; therefore, there is a possibility of an estimate bias that resulted in a wider Cl. Future research that is based on a greater sample size and forward-looking research design is necessary to provide in-depth insight into these points and strengthen environmental and public health monitoring.

\section{Conclusion}

This hospital-based case-control study revealed a few factors that influence the onset of lung cancer, including smoking, passive smoking, exposure to cooking oil fumes, family history of lung cancer, and medical history of lung disease. Increasing fruit intake, physical exercise, and drinking tea were found to be protective against lung cancer. More importantly, long-term exposure to $\mathrm{PM}_{10}, \mathrm{PM}_{2.5}$, and $\mathrm{O}_{3}$ is significantly associated with increased risk of lung cancer, and the risk appears to be greater in non-smokers than in smokers or the general population; moreover, this difference appears to be greater in people exposed to cooking oil fumes than those without.

\section{Declarations}

\section{Ethics approval and consent to participate}

This study was approved by the Institutional Review Board of Fujian Medical University (Fuzhou, China) and all participants signed informed consent forms.

\section{Consent for publication}

Not applicable

\section{Availability of data and material}

The datasets used and/or analyzed during the current study are available from the corresponding author on reasonable request.

\section{Competing interests}

The authors declare that they have no competing interests.

\section{Funding}

This study was supported by grants from the National Natural Science Foundation of China (Nos 81402738), Fujian Provincial Health Research Talents Training Programme Medical Innovation Project (Nos 2019-CX-33), Fujian Program for Outstanding Young Researchers in University awarded by Education Department of Fujian (Nos 2017B019) and National Major Science and Technology Program of China (Nos 2017ZX10103008).

\section{Authors' contributions}

CGM, HF and WJS conceived of the study, and carried out the experiments, participated in the drafted the manuscript. SJ, LZQ, and LJB collected samples. $\mathrm{XJF}, \mathrm{BL}, \mathrm{ZKC}$ and $\mathrm{CL}$ participated in the design of the study and helped to review the manuscript. CGM, HF and YHM performed the statistical analysis. All authors read and approved the final manuscript.

\section{Acknowledgements}

We thank all the staffs from Department of Thoracic Surgery, The first affiliated hospital of Fujian Medical University. And we also would like to express our appreciation to the patients participated in our study. 


\section{References}

1.Bray F, Ferlay J, Soerjomataram I, Siegel RL, Torre LA, Jemal A. Global cancer statistics 2018: GLOBOCAN estimates of incidence and mortality worldwide for 36 cancers in 185 countries. CA: A Cancer Journal for Clinicians 2018; 68(6): 394-424. https://doi.org/10.3322/caac.21492.

2.Chen W, Zheng R, Zhang S, et al. Cancer incidence and mortality in China in 2013: an analysis based on urbanization level. Chin J Cancer Res 2017; 29(1): 1-10. https://doi.org/10.21147/j.issn.1000-9604.2017.01.01.

3.Hitchman SC, Fong GT. Gender empowerment and female-to-male smoking prevalence ratios. Bulletin of the World Health Organization 2011; 89(3): 195202. https://doi.org/10.2471/BLT.10.079905.

4.Parkin DM, Bray F, Ferlay J, Pisani P. Global cancer statistics, 2002. CA Cancer J Clin 2005; 55(2): 74-108. https://doi.org/10.3322/canjclin.55.2.74.

5.Raaschou-Nielsen O, Andersen ZJ, Beelen R, et al. Air pollution and lung cancer incidence in 17 European cohorts: prospective analyses from the European Study of Cohorts for Air Pollution Effects (ESCAPE). The Lancet Oncology 2013; 14(9): 813-22. https://doi.org/10.1016/s1470-2045(13)70279-1.

6.Krusinska B, Hawrysz I, Wadolowska L, et al. Associations of Mediterranean Diet and a Posteriori Derived Dietary Patterns with Breast and Lung Cancer Risk: A Case-Control Study. Nutrients 2018; 10(4). https://doi.org/10.3390/nu10040470.

7.Makinson A, Tenon JC, Eymard-Duvernay S, et al. Human immunodeficiency virus infection and non-small cell lung cancer: survival and toxicity of antineoplastic chemotherapy in a cohort study. Journal of thoracic oncology: official publication of the International Association for the Study of Lung Cancer 2011; 6(6): 1022-9. https://doi.org/10.1097/JT0.0b013e318217b6e0.

8. de Oliveira THA, do Amaral CM, de Franca Sao Marcos B, et al. Presence and activity of HPV in primary lung cancer. Journal of cancer research and clinical oncology 2018; 144(12): 2367-76. https://doi.org/10.1007/s00432-018-2748-8.

9.Wang XR, Chiu YL, Qiu H, Au JS, Yu IT. The roles of smoking and cooking emissions in lung cancer risk among Chinese women in Hong Kong. Annals of oncology: official journal of the European Society for Medical Oncology 2009; 20(4): 746-51. https://doi.org/10.1093/annonc/mdn699.

10.Cote ML, Liu M, Bonassi S, et al. Increased risk of lung cancer in individuals with a family history of the disease: a pooled analysis from the International Lung Cancer Consortium. European journal of cancer (Oxford, England: 1990) 2012; 48(13): 1957-68. https://doi.org/10.1016/j.ejca.2012.01.038.

11.Ilar A, Plato N, Lewne M, Pershagen G, Gustavsson P. Occupational exposure to diesel motor exhaust and risk of lung cancer by histological subtype: a population-based case-control study in Swedish men. European journal of epidemiology 2017; 32(8): 711-9. https://doi.org/10.1007/s10654-017-0268-5.

12.Curwen MP, Kennaway EL, Kennaway NM. The incidence of cancer of the lung and larynx in urban and rural districts. British journal of cancer 1954; 8(2): 181-98. https://doi.org/10.1038/bjc.1954.18.

13.Cohen AJ, Ross Anderson H, Ostro B, et al. The global burden of disease due to outdoor air pollution. Journal of toxicology and environmental health Part A 2005; 68(13-14): 1301-7. https://doi.org/10.1080/15287390590936166.

14.Beelen R, Hoek G, van den Brandt PA, et al. Long-term exposure to traffic-related air pollution and lung cancer risk. Epidemiology (Cambridge, Mass) 2008; 19(5): 702-10. https://doi.org/10.1097/EDE.0b013e318181b3ca.

15.Brunekreef B, Beelen R, Hoek G, et al. Effects of long-term exposure to traffic-related air pollution on respiratory and cardiovascular mortality in the Netherlands: the NLCS-AIR study. Research report (Health Effects Institute) 2009; (139): 5-71; discussion73-89.

16.Cesaroni G, Badaloni C, Gariazzo C, et al. Long-term exposure to urban air pollution and mortality in a cohort of more than a million adults in Rome. Environmental health perspectives 2013; 121(3): 324-31. https://doi.org/10.1289/ehp.1205862.

17.Katanoda K, Sobue T, Satoh $\mathrm{H}$, et al. An association between long-term exposure to ambient air pollution and mortality from lung cancer and respiratory diseases in Japan. Journal of epidemiology 2011; 21(2): 132-43. https://doi.org/10.2188/jea.je20100098.

18.Naess O, Nafstad P, Aamodt G, Claussen B, Rosland P. Relation between concentration of air pollution and cause-specific mortality: four-year exposures to nitrogen dioxide and particulate matter pollutants in 470 neighborhoods in Oslo, Norway. American journal of epidemiology 2007; 165(4): $435-43$. https://doi.org/10.1093/aje/kwk016.

19.Naess O, Piro FN, Nafstad P, Smith GD, Leyland AH. Air pollution, social deprivation, and mortality: a multilevel cohort study. Epidemiology (Cambridge, Mass) 2007; 18(6): 686-94. https://doi.org/10.1097/ede.0b013e3181567d14.

20.He F, Xiao RD, Lin T, et al. Dietary patterns, BCMO1 polymorphisms, and primary lung cancer risk in a Han Chinese population: a case-control study in Southeast China. BMC cancer 2018; 18(1): 445. https://doi.org/10.1186/s12885-018-4361-2.

21.Dadvand P, Rankin J, Rushton S, Pless-Mulloli T. Ambient air pollution and congenital heart disease: a register-based study. Environmental research 2011; 111(3): 435-41. https://doi.org/10.1016/j.envres.2011.01.022. 
22.Chen R, Kan H, Chen B, et al. Association of particulate air pollution with daily mortality: the China Air Pollution and Health Effects Study. American journal of epidemiology 2012; 175(11): 1173-81. https://doi.org/10.1093/aje/kwr425.

23.Xu D, Cheng Y, Dong S, Guo C, Jang X, Zheng X. Systematic review and meta-analysis of the adverse health effects of ambient PM2.5 and PM10 pollution in the Chinese population. Environmental research 2015; 136: 196-204. https://doi.org/10.1016/j.envres.2014.06.029.

24.Cao J, Yang C, Li J, et al. Association between long-term exposure to outdoor air pollution and mortality in China: a cohort study. Journal of hazardous materials 2011; 186(2-3): 1594-600. https://doi.org/10.1016/j.jhazmat.2010.12.036.

25.Chen X, Zhang LW, Huang JJ, et al. Long-term exposure to urban air pollution and lung cancer mortality: A 12-year cohort study in Northern China. The Science of the total environment 2016; 571: 855-61. https://doi.org/10.1016/j.scitotenv.2016.07.064.

26.Wong CM, Tsang H, Lai HK, et al. Cancer Mortality Risks from Long-term Exposure to Ambient Fine Particle. Cancer epidemiology, biomarkers \& prevention: a publication of the American Association for Cancer Research, cosponsored by the American Society of Preventive Oncology 2016; 25(5): 839-45. https://doi.org/10.1158/1055-9965.epi-15-0626.

27.Zhou M, Liu Y, Wang L, Kuang X, Xu X, Kan H. Particulate air pollution and mortality in a cohort of Chinese men. Environmental pollution (Barking, Essex: 1987) 2014; 186: 1-6. https://doi.org/10.1016/j.envpol.2013.11.010.

28.Yang WS, Zhao H, Wang X, Deng Q, Fan WY, Wang L. An evidence-based assessment for the association between long-term exposure to outdoor air pollution and the risk of lung cancer. European journal of cancer prevention: the official journal of the European Cancer Prevention Organisation (ECP) 2016; 25(3): 163-72. https://doi.org/10.1097/cej.0000000000000158.

29.Fajersztajn L, Veras M, Barrozo LV, Saldiva P. Air pollution: a potentially modifiable risk factor for lung cancer. Nature reviews Cancer 2013; $13(9)$ : 674-8. https://doi.org/10.1038/nrc3572.

30.Xia Y, Fan L, Guan Y, Liu SY,Xiao Y. Progress in research of relationship between ambient air PM2.5 and lung diseases. Chinese Journal of Epidemiology2017;38(7): 993-996. https://doi.org/10.3760/cma.j.issn.0254-6450.2017.07.029.

31.Pope CA, 3rd, Burnett RT, Thun MJ, et al. Lung cancer, cardiopulmonary mortality, and long-term exposure to fine particulate air pollution. Jama 2002; 287(9): 1132-41.

32.Adam M, Schikowski T, Carsin AE, et al. Adult lung function and long-term air pollution exposure. ESCAPE: a multicentre cohort study and meta-analysis. The European respiratory journal 2015; 45(1): 38-50. https://doi.org/10.1001/jama.287.9.1132.

33.Hoek G, Raaschou-Nielsen O. Impact of fine particles in ambient air on lung cancer. Chin J Cancer 2014; 33(4): $197-203$.

https://doi.org/10.5732/cjc.014.10039.

34.Abbey DE, Nishino N, McDonnell WF, et al. Long-term inhalable particles and other air pollutants related to mortality in nonsmokers. American journal of respiratory and critical care medicine 1999; 159(2): 373-82. https://doi.org/10.1164/ajrccm.159.2.9806020.

35.Jerrett M, Burnett RT, Pope CA, 3rd, et al. Long-term ozone exposure and mortality. The New England journal of medicine 2009; 360(11): $1085-95$. https://doi.org/10.1056/NEJMoa0803894.

36.Carey IM, Atkinson RW, Kent AJ, van Staa T, Cook DG, Anderson HR. Mortality associations with long-term exposure to outdoor air pollution in a national English cohort. American journal of respiratory and critical care medicine 2013; 187(11): 1226-33. https://doi.org/10.1164/rccm.201210-1758oc.

37.Jerrett M, Burnett RT, Beckerman BS, et al. Spatial analysis of air pollution and mortality in California. American journal of respiratory and critical care medicine 2013; 188(5): 593-9. https://doi.org/10.1164/rccm.201303-0609oc.

38.Lipsett MJ, Ostro BD, Reynolds P, et al. Long-term exposure to air pollution and cardiorespiratory disease in the California teachers study cohort. American journal of respiratory and critical care medicine 2011; 184(7): 828-35. https://doi.org/10.1164/rccm.201012-2082oc.

39.Vanwinge C, Gilles C, Gerard C. A Role For Ozone Pollution In Lung Cancer Progression. Am J Respir Crit Care Med 2017; 195: A2352.

40.Yang L, Hou XY, Wei Y, Thai P, Chai F. Biomarkers of the health outcomes associated with ambient particulate matter exposure. The Science of the total environment 2017; 579: 1446-59. https://doi.org/10.1016/j.scitotenv.2016.11.146.

41.Li R, Kou X, Xie L, Cheng F, Geng H. Effects of ambient PM2.5 on pathological injury, inflammation, oxidative stress, metabolic enzyme activity, and expression of c-fos and c-jun in lungs of rats. Environ Sci Pollut Res Int 2015; 22(24): 20167-76. 20176. https://doi.org/10.1007/s11356-015-5222-z.

\section{Tables}


Table 1 Comparison of demographic characteristics between two groups in different populations

\begin{tabular}{|c|c|c|c|c|c|c|c|c|c|c|c|c|}
\hline \multirow[t]{2}{*}{ Variables } & \multicolumn{4}{|l|}{ Total } & \multicolumn{4}{|l|}{ Smoker } & \multicolumn{2}{|c|}{ Non-smoker } & & \\
\hline & Cases n(\%) & Control n(\%) & & $P$ & Cases n(\%) & Control n(\%) & & $P$ & Cases n(\%) & Control n(\%) & & \\
\hline Age (years,) & $59.34 \pm 9.94$ & $58.64 \pm 11.26$ & -1.473 & 0.141 & $60.82 \pm 9.27$ & $58.90 \pm 10.19$ & -3.030 & 0.003 & $57.24 \pm 10.47$ & $58.50 \pm 11.81$ & 1.746 & 0.08 \\
\hline Gender & & & 1.379 & 0.240 & & & 0.004 & 0.948 & & & 67.678 & $<0.0$ \\
\hline Female & $303(34.2)$ & $303(34.2)$ & & & $7(1.3)$ & $6(1.4)$ & & & $296(80.9)$ & $442(55.9)$ & & \\
\hline Nationality & & & 0.026 & 0.873 & & & 2.807 & 0.094 & & & 0.670 & 0.41 \\
\hline Han & $863(97.5)$ & $1191(97.6)$ & & & $505(97.3)$ & $424(98.8)$ & & & $358(97.8)$ & $767(97.0)$ & & \\
\hline Others & $22(2.5)$ & $29(2.4)$ & & & $14(2.7)$ & $5(1.2)$ & & & $8(2.2)$ & $24(3.0)$ & & \\
\hline Marital status & & & 1.547 & 0.214 & & & 1.025 & 0.311 & & & 0.001 & 0.97 \\
\hline Married & $824(93.1)$ & 1118(91.6) & & & $492(94.8)$ & $400(93.2)$ & & & $332(90.7)$ & $718(90.8)$ & & \\
\hline Single & $61(6.9)$ & $102(8.4)$ & & & $27(5.2)$ & $29(6.8)$ & & & $34(9.3)$ & $73(9.2)$ & & \\
\hline $\begin{array}{l}\text { Educational } \\
\text { status }\end{array}$ & & & 169.749 & $<0.001$ & & & 46.084 & $<0.001$ & & & 116.641 & $<0.0$ \\
\hline $\begin{array}{l}\text { Primary school } \\
\text { and below }\end{array}$ & $477(53.9)$ & $360(29.5)$ & & & $255(49.1)$ & 133(31.0) & & & $222(60.7)$ & $227(28.7)$ & & \\
\hline Middle school & $320(36.2)$ & $505(41.4)$ & & & $221(42.6)$ & $208(48.5)$ & & & $99(27.0)$ & $297(37.5)$ & & \\
\hline Occupation & & & 114.919 & $<0.001$ & & & 23.277 & $<0.001$ & & & 102.522 & $<0.0$ \\
\hline $\begin{array}{l}\text { Agriculture, } \\
\text { forestry, animal } \\
\text { husbandry and } \\
\text { fishery } \\
\text { personnel }\end{array}$ & $263(29.7)$ & $180(14.8)$ & & & $157(30.3)$ & $76(17.7)$ & & & $106(29.0)$ & $104(13.1)$ & & \\
\hline $\begin{array}{l}\text { Production of } \\
\text { transport } \\
\text { workers }\end{array}$ & $219(24.7)$ & $268(22.0)$ & & & $134(25.8)$ & $113(26.3)$ & & & $85(23.2)$ & $155(19.6)$ & & \\
\hline $\begin{array}{l}\text { Enterprises and } \\
\text { institutions } \\
\text { personnel }\end{array}$ & $241(27.2)$ & $573(47.0)$ & & & $159(30.6)$ & $175(40.8)$ & & & $82(22.4)$ & $398(50.3)$ & & \\
\hline $\begin{array}{l}\text { Business service } \\
\text { staff }\end{array}$ & $74(8.4)$ & $116(9.5)$ & & & $45(8.7)$ & $47(11.0)$ & & & $29(7.9)$ & $69(8.7)$ & & \\
\hline $\begin{array}{l}\text { Other and } \\
\text { unemployed }\end{array}$ & $88(9.9)$ & $83(6.8)$ & & & $24(4.6)$ & $18(4.2)$ & & & $64(17.5)$ & $65(8.2)$ & & \\
\hline BMI & & & 22.331 & $<0.001$ & & & 29.042 & $<0.001$ & & & 1.926 & 0.38 \\
\hline$\geq 24$ & $270(30.5)$ & $481(39.4)$ & & & $144(27.7)$ & $184(42.9)$ & & & $126(34.4)$ & $297(37.5)$ & & \\
\hline $\begin{array}{l}\text { Pathological } \\
\text { type }\end{array}$ & & & & & & & & & & & & \\
\hline Adenocarcinoma & $551(62.3)$ & & & & $253(48.7)$ & & & & $298(81.4)$ & & & \\
\hline $\begin{array}{l}\text { Squamous cell } \\
\text { carcinoma }\end{array}$ & $208(23.5)$ & & & & $177(34.1)$ & & & & $31(8.5)$ & & & \\
\hline Others & $126(14.2)$ & & & & $89(17.1)$ & & & & $37(10.1)$ & & & \\
\hline
\end{tabular}


le 2 Analysis of risk factors of lung cancer in different populations ${ }^{\mathrm{a}}$

\begin{tabular}{|c|c|c|c|c|c|c|}
\hline \multirow[t]{2}{*}{ tbles } & \multicolumn{2}{|l|}{ Total } & \multicolumn{2}{|l|}{ Smoker } & \multicolumn{2}{|l|}{ Non-smoker } \\
\hline & case/control & aOR $(95 \% C I)^{\mathrm{b}}$ & case/control & aOR $(95 \% C I)^{\mathrm{c}}$ & case/control & aOR $(95 \% C I)^{\mathrm{d}}$ \\
\hline \multicolumn{7}{|c|}{ ly history of lung cancer } \\
\hline & $825 / 1185$ & 1 & $490 / 421$ & 1 & $335 / 764$ & 1 \\
\hline & $60 / 35$ & $3.193(2.029-5.025)$ & $29 / 8$ & $3.601(1.584-8.187)$ & $31 / 27$ & $3.448(1.901-6.253)$ \\
\hline \multicolumn{7}{|c|}{ nal history of lung disease } \\
\hline & $761 / 1135$ & 1 & $431 / 381$ & 1 & $330 / 754$ & 1 \\
\hline & $124 / 85$ & $2.547(1.874-3.462)$ & $88 / 48$ & $1.647(1.105-2.457)$ & $36 / 37$ & $3.486(2.042-5.951)$ \\
\hline \multicolumn{7}{|c|}{ sing alcohol } \\
\hline & $608 / 942$ & 1 & $276 / 244$ & 1 & $332 / 698$ & 1 \\
\hline & $277 / 278$ & $1.568(1.277-1.925)$ & $243 / 185$ & $1.208(0.924-1.5580)$ & $34 / 93$ & $1.415(0.879-2.278)$ \\
\hline \multicolumn{7}{|l|}{ sing tea } \\
\hline & $464 / 596$ & 1 & $179 / 147$ & 1 & $285 / 449$ & 1 \\
\hline & $421 / 624$ & $1.088(0.905-1.309)$ & $340 / 282$ & $1.166(0.878-1.548)$ & $81 / 342$ & $0.588(0.432-0.799)$ \\
\hline \multicolumn{7}{|l|}{ ing } \\
\hline & $366 / 791$ & 1 & - & - & - & - \\
\hline & $519 / 429$ & $2.489(2.065-3.000)$ & - & - & - & - \\
\hline \multicolumn{7}{|l|}{ ve smoking } \\
\hline & $288 / 598$ & 1 & - & - & $157 / 466$ & 1 \\
\hline & $597 / 622$ & $1.933(1.601-2.332)$ & - & - & $209 / 325$ & $1.632(1.247-2.135)$ \\
\hline \multicolumn{7}{|c|}{ llating smell after renovation } \\
\hline & $789 / 1080$ & 1 & $464 / 369$ & 1 & $325 / 711$ & 1 \\
\hline & $96 / 140$ & $1.007(0.754-1.345)$ & $55 / 60$ & $0.797(0.530-1.198)$ & $41 / 80$ & $1.153(0.750-1.772)$ \\
\hline \multicolumn{7}{|c|}{ ing oil fume exposure } \\
\hline & $148 / 324$ & 1 & $87 / 110$ & 1 & $61 / 214$ & 1 \\
\hline & $737 / 896$ & $1.615(1.287-2.026)$ & $432 / 319$ & $1.487(1.070-2.067)$ & $305 / 577$ & $1.521(1.086-2.130)$ \\
\hline \multicolumn{7}{|c|}{ ical activity } \\
\hline & $683 / 683$ & 1 & $403 / 259$ & 1 & $280 / 424$ & 1 \\
\hline & $202 / 537$ & $0.428(0.350-0.524)$ & $116 / 170$ & $0.475(0.354-0.638)$ & $86 / 367$ & $0.437(0.325-0.588)$ \\
\hline \multicolumn{7}{|l|}{ intake } \\
\hline mes/week & $357 / 751$ & 1 & $208 / 219$ & 1 & $149 / 532$ & 1 \\
\hline mes/week & $528 / 469$ & $2.034(1.690-2.447)$ & $311 / 210$ & $1.447(1.106-1.893)$ & $217 / 259$ & $2.574(1.953-3.392)$ \\
\hline
\end{tabular}

a Each variable was run independently

b Adjusted for educational status, occupation, BMI

c Adjusted for age, educational status, occupation, BMI

d Adjusted for gender, educational status, occupation 
Table 3 Comparison of air pollutant exposure in two groups in different populations ${ }^{\mathrm{a}}$

\begin{tabular}{|c|c|c|c|c|c|c|}
\hline \multirow{2}{*}{$\begin{array}{l}\text { Variables } \\
\left(\mathrm{mg} / \mathrm{m}^{3}\right)\end{array}$} & \multicolumn{2}{|l|}{ Total } & \multicolumn{2}{|l|}{ Smoker } & \multicolumn{2}{|l|}{ Non-smoker } \\
\hline & case/control & aOR $(95 \% C I)^{\mathrm{b}}$ & case/control & $a O R(95 \% C I)^{\mathrm{c}}$ & case/control & aOR $(95 \% C I)^{\mathrm{d}}$ \\
\hline \multicolumn{7}{|l|}{$\mathrm{SO}_{2}$} \\
\hline$<0.011$ & $6 / 12$ & 1 & $1 / 6$ & 1 & $5 / 6$ & 1 \\
\hline $0.011-0.017$ & $617 / 840$ & $1.466(0.499-4.309)$ & $361 / 285$ & $5.674(0.640-50.333)$ & $256 / 555$ & $0.637(0.150-2.704)$ \\
\hline $0.017-0.023$ & $170 / 246$ & $1.186(0.397-3.541)$ & $101 / 90$ & $4.953(0.550-44.602)$ & $69 / 156$ & $0.503(0.115-2.191)$ \\
\hline$>0.023$ & $78 / 106$ & $1.347(0.438-4.141)$ & $46 / 42$ & $5.288(0.572-48.855)$ & $32 / 64$ & $0.601(0.131-2.751)$ \\
\hline Continuous & & $<0.001(<0.001-3.315)$ & & - & & - \\
\hline \multicolumn{7}{|l|}{$\mathrm{NO}_{2}$} \\
\hline$<0.019$ & $310 / 229$ & 1 & $127 / 108$ & 1 & $102 / 202$ & 1 \\
\hline $0.019-0.029$ & $236 / 250$ & $1.356(1.028-1.788)$ & $156 / 88$ & $1.447(0.975-2.147)$ & $97 / 148$ & $1.241(0.831-1.853)$ \\
\hline $0.029-0.038$ & $257 / 443$ & $0.862(0.666-1.115)$ & $143 / 146$ & $0.804(0.555-1.165)$ & $114 / 297$ & $0.893(0.617-1.293)$ \\
\hline$>0.038$ & $139 / 215$ & $0.889(0.653-1.209)$ & $90 / 81$ & $0.854(0.559-1.304)$ & $49 / 134$ & $0.961(0.605-1.529)$ \\
\hline Continuous & & $<0.001(<0.001-1.000)$ & & $<0.001(<0.001-0.977)$ & & - \\
\hline \multicolumn{7}{|l|}{$\mathrm{PM}_{10}$} \\
\hline$<0.051$ & $79 / 166$ & 1 & $49 / 64$ & 1 & $30 / 102$ & 1 \\
\hline $0.051-0.057$ & $316 / 287$ & $2.450(1.728-3.474)$ & $181 / 97$ & $2.571(1.591-4.153)$ & $135 / 190$ & $2.366(1.395-4.014)$ \\
\hline $0.057-0.064$ & $438 / 667$ & $1.637(1.178-2.276)$ & $259 / 231$ & $1.517(0.974-2.363)$ & $179 / 436$ & $1.795(1.083-2.975)$ \\
\hline$>0.064$ & $36 / 83$ & $0.975(0.575-1.653)$ & $22 / 31$ & $1.042(0.513-2.116)$ & $14 / 52$ & $0.946(0.415-2.158)$ \\
\hline Continuous & & - & & - & & - \\
\hline \multicolumn{7}{|l|}{$\mathrm{PM}_{2.5}$} \\
\hline$<0.020$ & $8 / 132$ & 1 & $5 / 19$ & 1 & $3 / 113$ & 1 \\
\hline $0.020-0.027$ & $397 / 101$ & $33.658(15.450-73.325)$ & $260 / 41$ & $24.545(8.112-74.265)$ & $137 / 60$ & $61.431(18.041-209.181)$ \\
\hline $0.027-0.035$ & $497 / 987$ & $5.059(2.390-10.712)$ & $253 / 369$ & $2.630(0.910-7.595)$ & $226 / 618$ & $11.814(3.622-38.540)$ \\
\hline$>0.035$ & $0 / 0$ & - & $0 / 0$ & - & $0 / 0$ & - \\
\hline Continuous & & $0.001(<0.001-877.108)$ & & - & & - \\
\hline \multicolumn{7}{|l|}{$\mathrm{CO}$} \\
\hline$<0.491$ & $0 / 128$ & 1 & $0 / 18$ & 1 & $0 / 110$ & 1 \\
\hline $0.491-0.681$ & $342 / 74$ & - & $221 / 36$ & - & $121 / 38$ & - \\
\hline $0.681-0.871$ & $542 / 1018$ & - & $297 / 375$ & - & $245 / 643$ & - \\
\hline$>0.871$ & $0 / 0$ & - & $0 / 0$ & - & $0 / 0$ & - \\
\hline Continuous & & $0.839(0.481-1.466)$ & & $0.042(0.006-0.311)$ & & $2.882(1.306-6.360)$ \\
\hline \multicolumn{7}{|l|}{$\mathrm{O}_{3}$} \\
\hline$<0.047$ & $2 / 129$ & 1 & $0 / 18$ & 1 & $2 / 111$ & 1 \\
\hline $0.047-0.065$ & $367 / 86$ & $125.056(29.902-523.012)$ & $243 / 38$ & - & $124 / 48$ & $95.041(21.772--414.879)$ \\
\hline $0.065-0.083$ & $479 / 984$ & $17.746(4.322-72.862)$ & $255 / 368$ & - & $224 / 616$ & $17.068(4.084-71.342)$ \\
\hline$>0.083$ & $36 / 21$ & $50.896(11.069-234.032)$ & $5 / 20$ & - & $16 / 16$ & $37.313(7.301-190.700)$ \\
\hline Continuous & & - & & $<0.001(<0.001-0.001)$ & & - \\
\hline
\end{tabular}

a Each variable was run independently

b Adjusted for educational status, occupation, BMI, family history of lung cancer, medical history of lung disease, drinking alcohol, smoking, passive smoking, exposure to cooking oil fumes, physical exercise, and fruit consumption

c Adjusted for age, educational status, occupation, BMI family history of lung cancer, and medical history of lung disease, exposure to cooking oil fumes, physical exercise, and fruit intake

d Adjusted for gender, educational status, occupation, family history of lung cancer, medical history of lung disease, passive smoking, exposure to cooking oil fumes, drinking tea, physical exercise, and fruit intake

Table 4 Multivariate logistic regression analysis of lung cancer in total population 


\begin{tabular}{lllllll}
\hline Variables & $\beta$ & $\mathrm{S} . \mathrm{E}$ & Wald $\chi^{2}$ & $\mathrm{P}$ & $\mathrm{OR}^{\square}$ & $95 \% \mathrm{CI}^{\square}$ \\
\hline Family history of lung cancer & 1.399 & 0.290 & 23.222 & $<0.001$ & 4.051 & $2.293-7.155$ \\
\hline Personal history of lung disease & 0.878 & 0.182 & 23.305 & $<0.001$ & 2.405 & $1.684-3.435$ \\
\hline Smoking & 0.502 & 0.115 & 19.099 & $<0.001$ & 1.653 & $1.319-2.070$ \\
\hline Physical activity & -0.894 & 0.122 & 53.364 & $<0.001$ & 0.409 & $0.322-0.520$ \\
\hline Cooking oil fume exposure & 0.396 & 0.137 & 8.330 & 0.004 & 1.486 & $1.136-1.945$ \\
\hline Passive smoking & 0.239 & 0.117 & 4.171 & 0.041 & 1.270 & $1.01-1.598$ \\
\hline Fruit intake & 0.523 & 0.112 & 21.913 & $<0.001$ & 1.686 & $1.355-2.099$ \\
\hline $\mathrm{O}_{3}\left(\mathrm{mg} / \mathrm{m}^{3}\right)$ & & & 25.979 & $<0.001$ & & \\
$0.047-0.065$ & 3.701 & 0.884 & 17.516 & $<0.001$ & 40.493 & $7.155-229.155$ \\
$0.065-0.083$ & 2.749 & 0.942 & 8.525 & 0.004 & 15.635 & $2.469-99.007$ \\
$>0.083$ & 3.083 & 0.943 & 10.687 & 0.001 & 21.818 & $3.437-138.515$ \\
\hline $\mathrm{PM}_{2.5}\left(\mathrm{mg} / \mathrm{m}^{3}\right)$ & & & 19.510 & $<0.001$ & & \\
\hline $0.020-0.027$ & 1.575 & 0.612 & 6.628 & 0.010 & 4.829 & $1.456-16.015$ \\
\hline $0.027-0.035$ & 0.398 & 0.684 & 0.339 & 0.560 & 1.489 & $0.39-5.688$ \\
\hline $\mathrm{PM}$ & & & 34.179 & $<0.001$ & & \\
\hline $0.051-0.057$ & 1.064 & 0.218 & 23.827 & $<0.001$ & 2.898 & $1.891-4.444$ \\
\hline $0.057-0.064$ & 1.252 & 0.273 & 21.111 & $<0.001$ & 3.499 & $2.051-5.969$ \\
\hline$>0.064$ & 0.193 & 0.300 & 0.415 & 0.519 & 1.213 & $0.674-2.185$ \\
\hline Constant & -4.018 & 0.785 & 26.194 & $<0.001$ & 0.018 & \\
\hline
\end{tabular}

uUnconditional logistic regression with the backward stepwise method

Table 5 Multivariate logistic regression analysis of lung cancer in smokers

\begin{tabular}{lllllll}
\hline Variables & $\beta$ & $\mathrm{S} . \mathrm{E}$ & $\mathrm{Wald} \chi^{2}$ & $\mathrm{P}$ & $\mathrm{OR}^{\square}$ & $95 \% \mathrm{CI}^{\square}$ \\
\hline Family history of lung cancer & 1.599 & 0.504 & 10.063 & 0.002 & 4.947 & $1.842-13.285$ \\
Personal history of lung disease & 0.585 & 0.234 & 6.270 & 0.012 & 1.796 & $1.136-2.84$ \\
\hline Physical activity & -0.890 & 0.178 & 24.998 & $<0.001$ & 0.411 & $0.29-0.582$ \\
\hline Fruit intake & 0.280 & 0.161 & 3.026 & 0.082 & 1.323 & $0.965-1.813$ \\
\hline $\mathrm{PM}_{2.5}\left(\mathrm{mg} / \mathrm{m}^{3}\right)$ & & & 137.807 & $<0.001$ & & \\
$0.020-0.027$ & 3.399 & 0.580 & 34.317 & $<0.001$ & 29.947 & $9.603-93.392$ \\
$0.027-0.035$ & 1.016 & 0.554 & 3.370 & 0.066 & 2.763 & $0.934-8.175$ \\
$\mathrm{PM}_{10}\left(\mathrm{mg} / \mathrm{m}^{3}\right)$ & & & 24.844 & $<0.001$ & & \\
$0.051-0.057$ & 1.285 & 0.280 & 21.030 & $<0.001$ & 3.614 & $2.087-6.258$ \\
\hline $0.057-0.064$ & 0.781 & 0.260 & 9.018 & 0.003 & 2.184 & $1.312-3.636$ \\
\hline$>0.064$ & 0.200 & 0.412 & 0.235 & 0.628 & 1.221 & $0.545-2.738$ \\
\hline Constant & -2.321 & 0.832 & 7.782 & 0.005 & 0.098 & \\
\hline
\end{tabular}

पUnconditional logistic regression with the backward stepwise method

Table 6 Multivariate logistic regression analysis of lung cancer in non-smokers

\begin{tabular}{lllllll}
\hline Variables & $\beta$ & $\mathrm{S} . \mathrm{E}$ & $\mathrm{Wald} \chi^{2}$ & $\mathrm{P}$ & $\mathrm{OR}^{\square}$ & $95 \% \mathrm{CI}^{\square}$ \\
\hline Family history of lung cancer & 1.357 & 0.364 & 13.878 & $<0.001$ & 3.885 & $1.902-7.933$ \\
Personal history of lung disease & 1.239 & 0.313 & 15.667 & $<0.001$ & 3.451 & $1.869-6.373$ \\
\hline Physical activity & -0.841 & 0.176 & 22.935 & $<0.001$ & 0.431 & $0.306-0.608$ \\
\hline Cooking oil fume exposure & 0.506 & 0.201 & 6.331 & 0.012 & 1.658 & $1.118-2.458$ \\
\hline Fruit intake & 0.749 & 0.161 & 21.705 & $<0.001$ & 2.115 & $1.544-2.899$ \\
\hline Drinking tea & -0.512 & 0.183 & 7.849 & 0.005 & 0.599 & $0.419-0.857$ \\
\hline $\mathrm{PM}_{2.5}\left(\mathrm{mg} / \mathrm{m}^{3}\right)$ & & & 10.692 & 0.005 & & \\
$0.020-0.027$ & 2.499 & 0.891 & 7.869 & 0.005 & 12.173 & $2.123-69.788$ \\
$0.027-0.035$ & 1.681 & 1.002 & 2.813 & 0.093 & 5.372 & $0.753-38.311$ \\
\hline $\mathrm{PM}_{10}\left(\mathrm{mg} / \mathrm{m}^{3}\right)$ & & & 14.721 & 0.002 & & \\
\hline $0.051-0.057$ & 0.874 & 0.287 & 9.262 & 0.002 & 2.397 & $1.365-4.208$ \\
\hline $0.057-0.064$ & 0.814 & 0.272 & 8.976 & 0.003 & 2.258 & $1.325-3.847$ \\
\hline$>0.064$ & -0.038 & 0.438 & 0.008 & 0.931 & 0.963 & $0.408-2.27$ \\
\hline $\mathrm{O}_{3}\left(\mathrm{mg} / \mathrm{m}^{3}\right)$ & & & 12.585 & 0.006 & & \\
\hline $0.047-0.065$ & 2.619 & 1.032 & 6.443 & 0.011 & 13.721 & $1.816-103.662$ \\
\hline $0.065-0.083$ & 1.493 & 1.135 & 1.731 & 0.188 & 4.450 & $0.481-41.15$ \\
\hline$>0.083$ & 1.697 & 1.123 & 2.283 & 0.131 & 5.458 & $0.604-49.339$ \\
\hline Constant & -6.482 & 0.929 & 48.680 & $<0.001$ & 0.002 & \\
\hline
\end{tabular}

uUnconditional logistic regression with the backward stepwise method

\section{Figures}




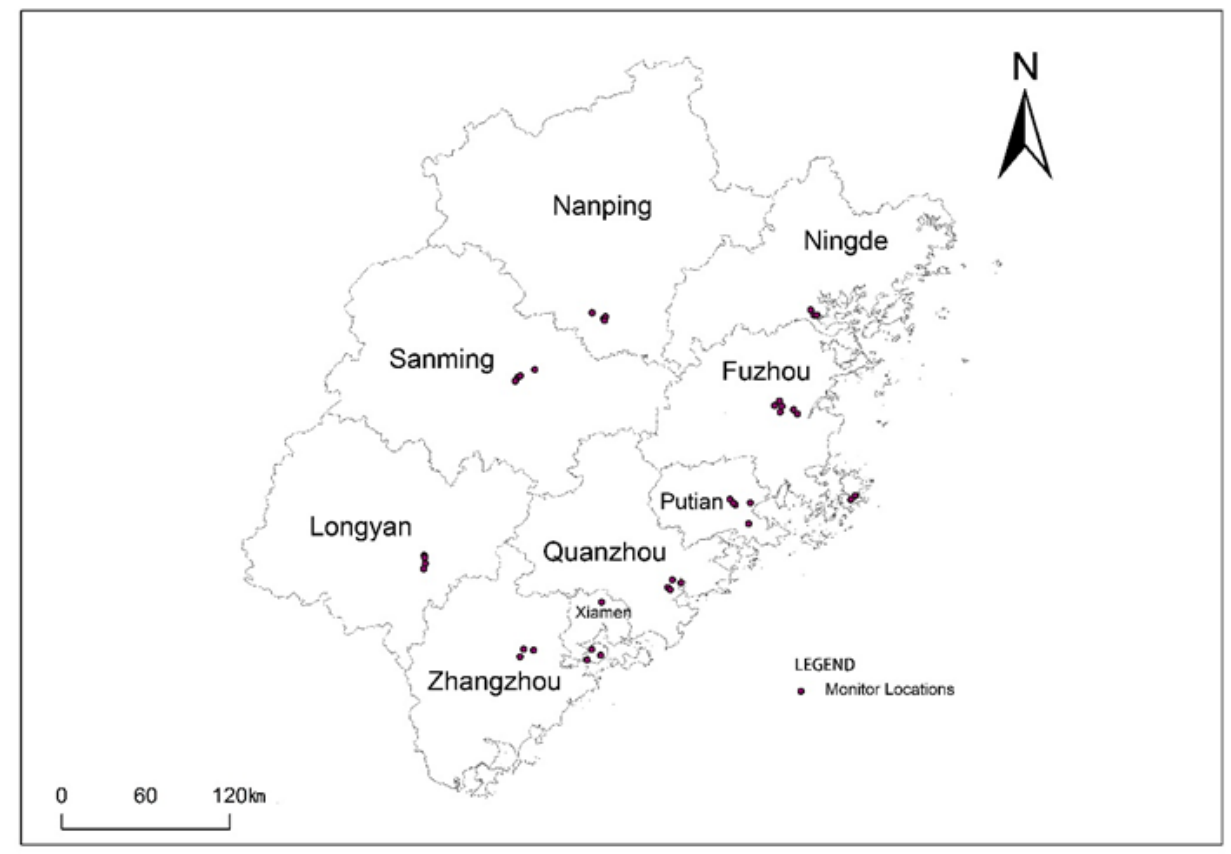

Figure 1

Map of the monitoring sites in Fujian Province, China Note: The designations employed and the presentation of the material on this map do not imply the expression of any opinion whatsoever on the part of Research Square concerning the legal status of any country, territory, city or area or of its authorities, or concerning the delimitation of its frontiers or boundaries. This map has been provided by the authors.
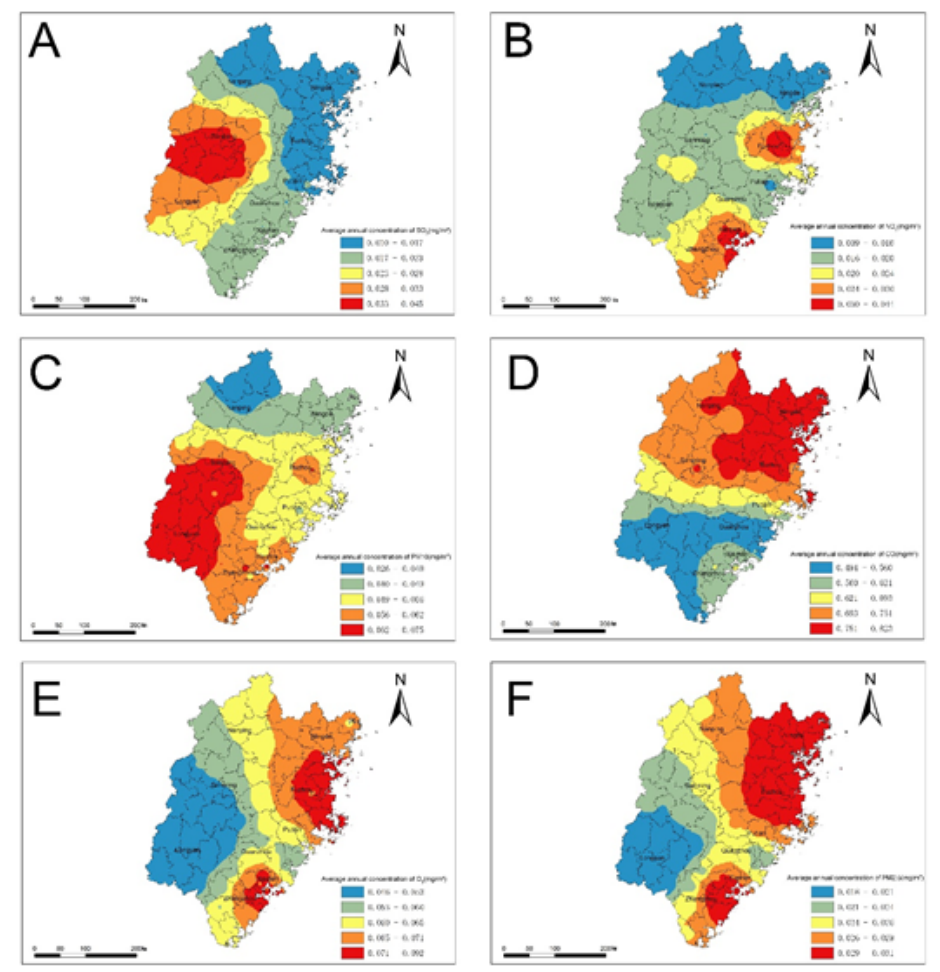

Figure 2

Annual average of SO2, NO2 and PM10 concentrations in 2005-2015 and CO, PM2.5, and 03 concentrations in 2013-2015 Note: The designations employed and the presentation of the material on this map do not imply the expression of any opinion whatsoever on the part of Research Square concerning the legal status of any country, territory, city or area or of its authorities, or concerning the delimitation of its frontiers or boundaries. This map has been provided by the authors.

\section{Supplementary Files}


This is a list of supplementary files associated with this preprint. Click to download.

- AdditionalTables.docx

Page $14 / 14$ 